\title{
Auf einen Blick
}

\section{Nicht heilendes induriertes Ulkus an der Unterlippe}

\author{
ANDREAs HutschenReuther, Christian Rose
}

Immunsupprimierte Patienten weisen immer wieder Hauterkrankungen mit atypischen Verläufen auf, denen mit den gewohnten diagnostischen Überlegungen nicht so leicht beizukommen ist. In unserem Beispiel sorgte erst die histologische Untersuchung der Probebiopsie für Klarheit.

$\mathrm{E}$ in 69-jähriger Patient stellt sich mit einem langsam größenprogredienten, indurierten Ulkus an der Unterlippe vor. Nach einer Herztransplantation mit notwendiger Immunsuppression waren in der Vergangenheit an verschiedenen Lokalisationen Plattenepithelkarzinome und Basalzellkarzinome an der Haut entfernt worden. Zum Ausschluss eines Plattenepithelkarzinoms der Unterlippe erfolgte eine Probebiopsie.

\section{Diagnose: Vegetierende Herpes- simplex-Infektion}

Nach histologischer Sicherung erfolgte die antivirale Therapie mit Valaciclovir, worunter es zu einer langsamen Abheilung kam.
Bei immunsupprimierten Patienten kann eine Herpes simplex-Infektion atypische Verläufe zeigen. Bei nicht heilenden Ulzerationen mit Nekrosen sollte an eine atypische persistierende HSVInfektion gedacht werden. Schmerzen und vergrößerte regionale Lymphknoten können fehlen. Der immunfluoreszenzoptische Erregernachweis aus diesen Läsionen kann falsch negativ ausfallen. Wie im vorgestellten Fall kann eine histologische Untersuchung die Diagnose sichern. Hierbei sollte der Rand der Ulzeration biopsiert werden. Dem Histologen sollte unbedingt mitgeteilt werden, dass bei dem Patienten eine chronische Immunsuppression besteht. In diesem Fall fanden sich die typischen zytopa- thischen Veränderungen mit mehrkernigen Keratinozyten mit stahlgrauen Kernen. Diese histologischen Veränderungen lassen sich oft erst nach vorsichtiger Aufarbeitung in Serienschnitten darstellen.

\section{Literatur:}

1. Wolf IH. Hautinfektion nach Transplantationen. Hautarzt 2010; 61: 230-233.

2. Kern WV, Wagner D, Hirsch HH. Infektionen nach Organtransplantation. Internist 2005; 46: 630-42.

\section{Priv.-Doz. Dr. Christian Rose}

Dermatohistologisches Einsendelabor Maria-Goeppert-Str. 1

23562 Lübeck

E-Mail: rose@dermatohistologie-luebeck.de

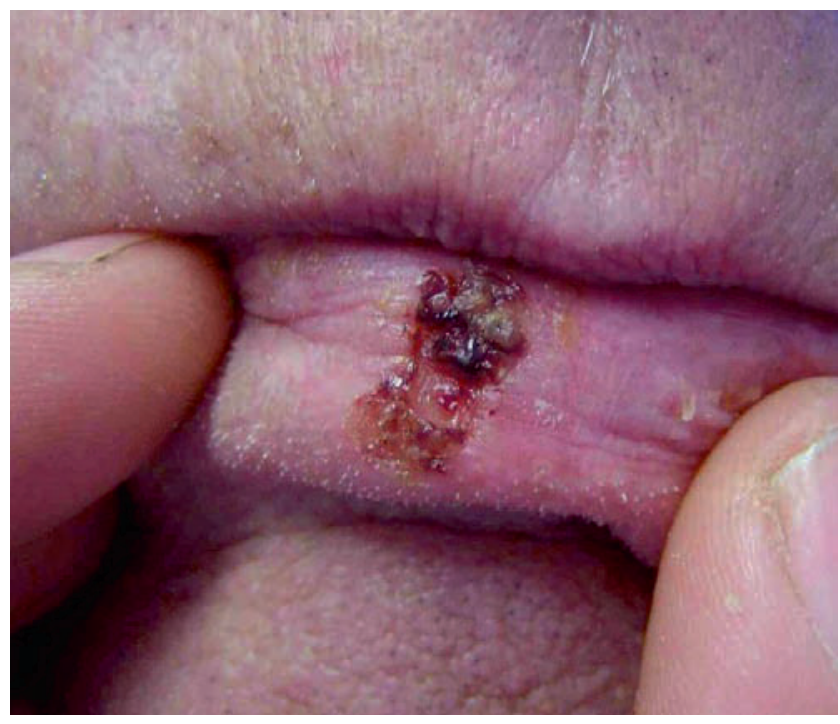

Abb. 1a: Krustig belegtes Ulkus an der Unterlippe

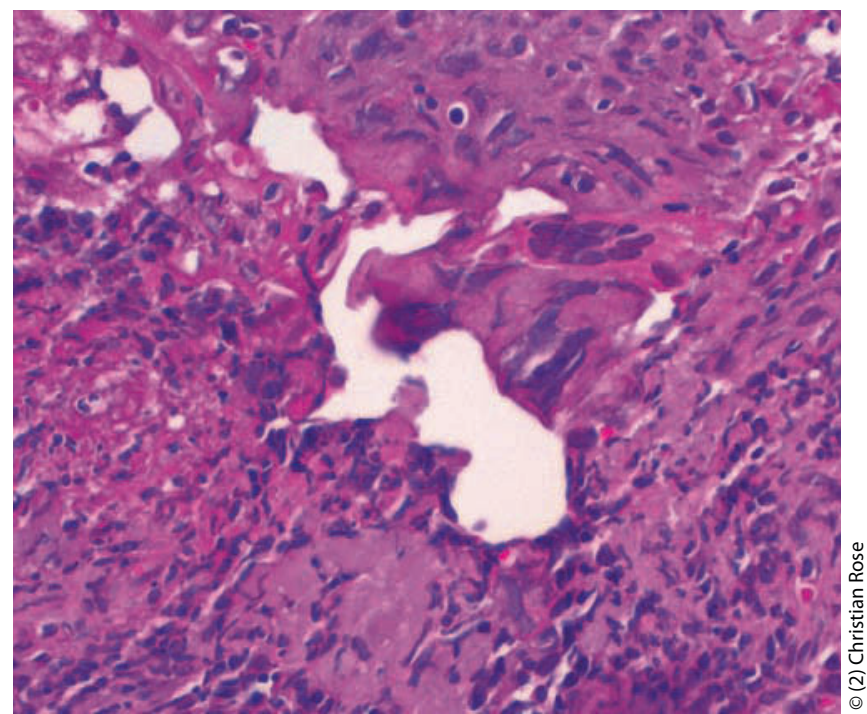

Abb. 1b: Histologie: Zytopathische Effekte einer Herpes-Infektion 